\title{
The City of Alexandria: Its Identity and Environment in the works of Alexandria's Pioneer Painters
}

\author{
DOI: $10.21625 /$ archive.v1i1.136
}

\section{Laila Abu El Seoud Mohamed Fadl ${ }^{1}$}

${ }^{1}$ Lecturer of painting Department - Faculty of Fine Arts in Cairo

\section{Keywords}

Alexandria city; Identity; Environment;Said

Wanly; Aweys

\begin{abstract}
The unique location of Alexandria city in the Mediterranean Basin has attracted several artistic civilizations ever since the time of Ptolemy. This has been the case during the Roman era, and the subsequent eras throughout which Alexandria remained the window of Egypt and most of the Middle East to the European cultures and arts. As a result, Alexandria has witnessed the cultural and artistic renaissance during the second half of the nineteenth century and the first half of the twentieth century, since "Muhammad Ali" -and his family-permitted the foreign delegations to come and form colonies fused with the human component of Alexandria that had a unique character. Consequently, the foreign artists' rooms were widely spread and the Alexandrian pioneers of painting art, of the first and second generations, studied under their supervision. Despite being trained by foreigners, their sense of belonging to the Egyptian identity or their participation in laying a groundwork for a national art project deeply rooted in the heritage of the nation wasn't affected. However, they were receptive to maturely cope with the modernityof the western schools of arts. Mahmoud Said, a painter, after completing the art foundation phase, employed his art to portray the modern Egyptian man as a national hero. This portrayal was possible through his use of environmetal elements and characters. Seif Wanli was one of the most receptive Egyptian painters to the modern and contemporary western schools of art. He was allegedly known to be unconcerned with the issue of national identity, however, Alexandria kept its high rank in his art despite being characterized by global features. Adham Wanli remained loyal to his impressive and symbolic realism as Alexandria, with all its components, was the core of his artistic creativity. Hamid Aweys left his hometown and went to Alexandria and spent most of his age therein. His belonging to the identity and environment of that ancient coastal city was the same as that of the previously-mentioned artists. He was inspired by the city’s environmental and cultural elements in a distinctive way.
\end{abstract}

\section{Introduction}

The city of Alexandria was considered one of the ancient capitals of culture in the world. It was known to be a meeting place and a link between the great civilizations of the world. The people of Alexandria were knowledgeable in various cultural fields including the ancient Egyptian, Persian, Greek, Romanian and Islamic civilizations. All these civilizations merged to shape the culture of Alexandria, the bride of the Mediterranean Sea throughout the ages, making it a beacon of culture and art, and a citadel of science and literature. 


\begin{abstract}
About this research: This research sheds lights on the pioneers of painting in Alexandria, Egypt. This paper especially focuses on the artists "Mahmoud Said", and the brothers "Wanli" and "Hamid Aweys", who built their career on the concept of identity and contributed to building the national identity of modern Egyptian painting.
\end{abstract}

The aim of the research: This research aims to highlight the different aspects of the coastal environment of Alexandria and their impact on the works of the pioneers of Alexandrian painting. It also aims to deduce the successive cultural influences on the city of Alexandria and the artists' impact on the city itself.

The importance of this research: The city of Alexandria itself is what makes this paper significant. Alexandria is where the momentum of art began on a global scale given the multiplicity of ceremonies and foreign artists who have made it a great school of art, which consequently reproduced the pioneers of contemporary Egyptian art.

The limitations of this research: The spatial boundaries of the city of Alexandria were the only limitation.

Research Methodology: The methodology is a unit of research in its entirety and it's considered as a separate, continuous, analytical study.

\title{
Alexandria, the platform for Fine Arts
}

The city of Alexandria is known for being a leader in the Fine Arts given the various forms of art dispersed all over the city including paintings, murals, and/or sculptures. A festival that was founded by foreign artists to teach new generations was also held in Alexandria. The civilizations embedded in this city undoubtedly influenced the psych of Alexandrian artists; the Greek and Romanian civilizations in particular have inspired artists in their artistic endeavors. The nature of this coastal city, the rainy weather, the atmosphere, and the seas and beaches have all inspired Alexandrian artists.

\section{The history of Fine Arts in Alexandria}

There are two different eras in the history of Alexandria, the first being the pre July 1952 era, and the other being the times after the revolution. Before the revolution, Alexandria was occupied by several European communities comprised of business men who had distinct artistic customs. Nationalization encouraged these European artists to interact with the Egyptian communities and teach them all about Fine Arts. These European artists also contributed to the beginning of the Fine Arts movement in Alexandria in the beginning of the twentieth century.

Art Galleries of the city walls were opened for the masses and Egyptian artists who were deprived of them before the revolution were permitted to attend thereafter. In less than five years after the July $23^{\text {rd }}$ revolution of 1952 , the Faculty of Fine Arts was established to fill the gap left by immigrant artists who left the country. A broad base of fine artists appeared, including the artists who effectively contributed to establishing an artistic movement. Their role was to enrich the fine arts movement using constructive criticism, commentaries, and constant evaluations, and of course, create a link between artists and the general public. The Faculty of Fine Arts was successful in its mission, and several generations of artists graduated from there and spread out all over Alexandria and successfully worked in different fields given that they are distinct in terms of their ideas and artistic senses that are influenced by Alexandrian streets.

The city of Alexandria has produced the geniuses of art, which is the artistic capital of Egypt, with all its cultural and social components.

During the second half of the nineteenth and the first half of the twentieth century, Alexandria witnessed an artistic and cultural renaissance. The purpose of this research is to shed light on the environment of Alexandria, the origin ad status of various Alexandrian artists, and the impact of the artists' work on the city.

\section{The artist "Mahmoud Said" (1897-1964)}

He was one of the most important artists in Alexandria who studied under the foreign artists' ceremony in Alexandria and studied under a painter named "Arto Zagniery." His educational background enhanced his talents and taught him influential construction concepts that have made the shapes in his paintings seem more solid and well established.

The city of Alexandria and its people played a significant role in shaping his work. Alexandria is the city of "Said"; his paintings and his use of colors, spaces, shadows, and light were inspired by alleys in a popular neighborhood in which a local girl, known as the 'country girl' lived; she was his muse.

Even though the Alexandria was known for and symbolized by the lighthouse that guided sailors, the artist "Mahmoud Said" was able to make the 'country girl' a slogan for the city that competed with the lighthouse.

Mahmoud Said's painting titled "blue robe" (1927) Figure (1) featuring an Alexandrian woman with an authentic Egyptian face, a head scarf, and a simple blue dress that is the color of the sea and it indicates calmness and serenity and is inspired by the pharaohs without being plagiarized . In Greek and Romanian statues, the sculpted 
men had small heads and very muscular bodies which represents violent movements. In this painting, the woman portrayed has a small head yet long relatively muscular arms which strongly suggests that she is a working woman.

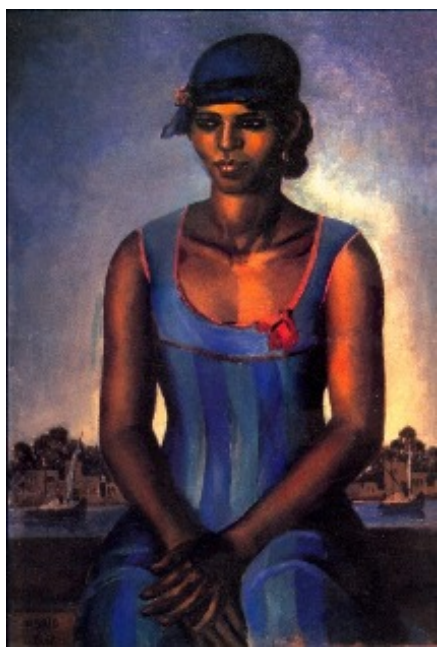

Figure (1)

During the 1930's, Said went to an Egyptian neighborhood named “Anfoushi” where he featured beautiful local women in his paintings.

In his painting called "beautiful sea" (1935) Figure (2), he featured three beautiful women from Anfoushi, resembling the same feminine beauty that flourished during the 1930s, in which women's portraits were made. Despite the fact that they were closely associated with the environment, the artist's own vision covered the painting with a kind of magic. The existence of Eastern women was closely associated with the emergence of Alexandria as the bride of the Mediterranean Sea

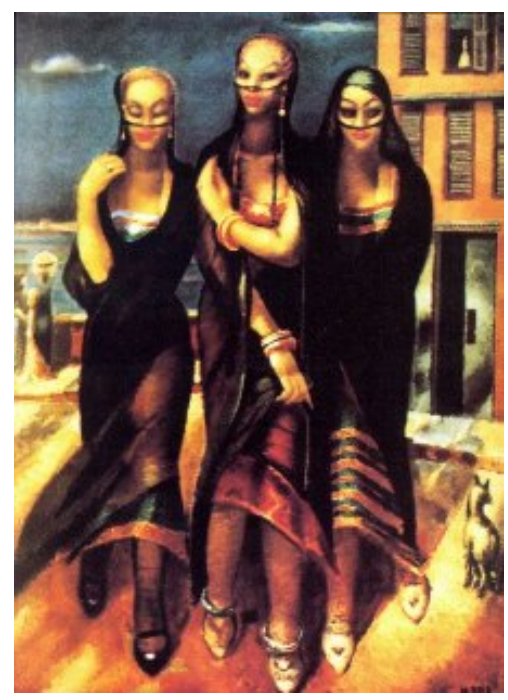

Figure (2)

He was later fascinated by fishermen and discovered the joy of living among them while they set out to catch fish in broad daylight where the sun shines on the blue sea water and makes it sparkle like diamonds.

We the see the painting "strange fishing" (1933) - Figure (3) in which the characters and elements were shaped like rigid stone statues. The sea and the fishing environment gave him a mysterious metaphysical sense that corresponded to the philosophical dimensions of the subject as opposed to the infinite movement of the hunters in the track ring. 


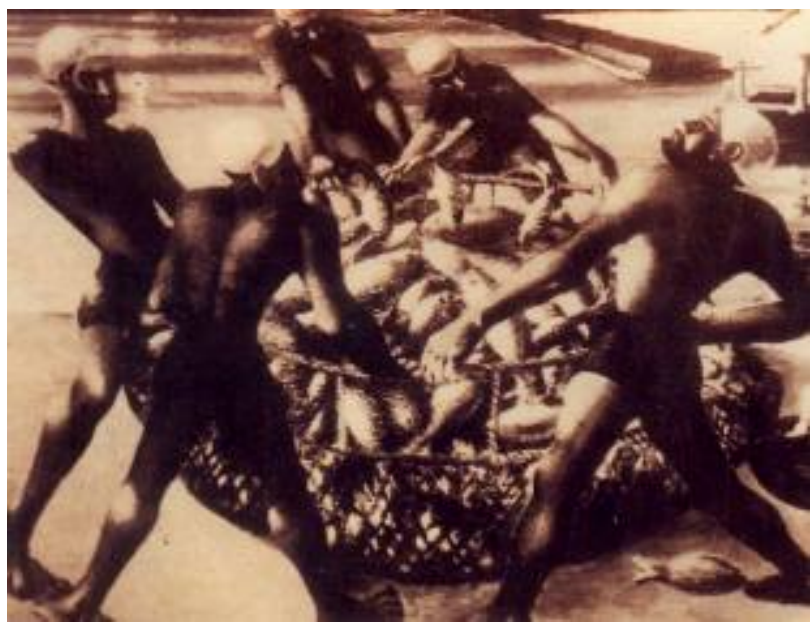

Figure (3)

\section{The Brothers: Seif and Adham Wanli}

Moving on to the two brothers, "Seif Wanli" (1906 -1979) and "Adham Wanli" (1908 - 1961)," we find that when the city of Alexandria was full of foreign artists and their own ateliers and workshops in 1925, The Italian artist, "Atureanu Becky," whom they had already known before, started his own workshop and the two brothers were among the first to join.

The brothers were among artists who were the most tolerant and accepting to modern European art and its schools including: cubism, abstraction, brutality, parents, diaries, surrealism and futurism given where they reside overlooking Alexandria’s beach toward the other shores of the Mediterranean Sea.

The creativity of the two brothers lied in the experimentation in the language of form and artistic construction through the visualization of reality until the art is an aesthetic value for its own sense of fantasy influenced by their love for music, ballet, opera and performing arts. They were keen on watching foreign performances that came to Alexandria on a continuous basis and the expression and they were greatly affected by them.

We find the painting of "Opera Regilito" (1948) Figure (4) by the artist, "Seif Wanli", in which he was concerned with the portrayal of the old European-style play, which is linked to the French novel by Victor Hugo, entitled "The King is Lightening" more than the heroes of the work. It's as if it depicts one of the historic buildings in the city of Alexandria, confirming that it maintains its place within sophisticated and fine arts.

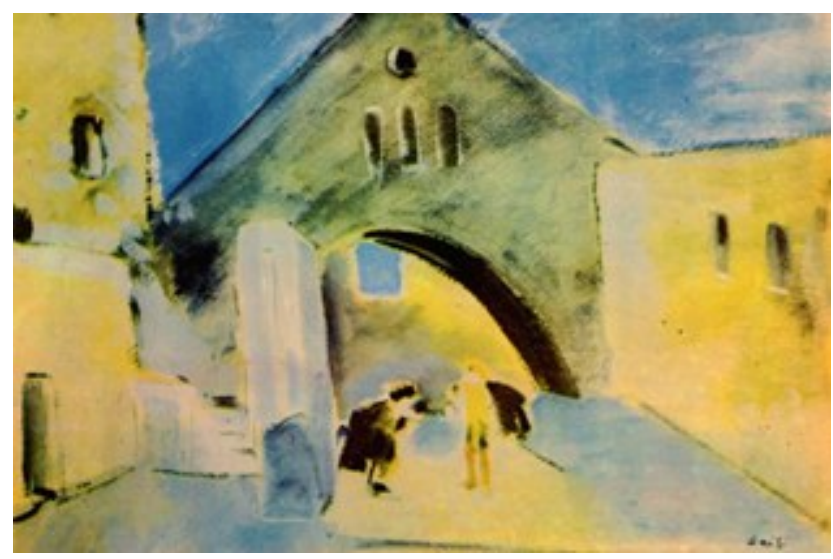

Figure (4)

When the sea is mentioned in modern Egyptian paintings, no one is more entitled to talk about his or her work other than the artist "Mahmoud Said," except the artist "Saif Wanli," who not only borrowed the colors, clarity and transparency of Alexandria Sea, the one who is more deserving of talking about his offerings in this regard after the artist "Mahmoud Said," one artist who is "Seif Wanli" who not only that borrows the colors, clarity and transparency of Alexandria Sea, but his works were also like a lighthouse and its well-established Ghadian ships. He deserves the title of "Artist of Alexandria" and when we do so, we have noticed a fundamental element in his character and understanding of the cause of this renewal and diversity in his productions. 
Wanli was very interested in nature and was frequently in the outdoors. In his art work, his favorite subjects were the port of Alexandria port, containers, workers' movements, boats and boats anchored on the pavement such as Manri in the "Alexandria Port" (1952) were depicted as a realistic painting by the artist.

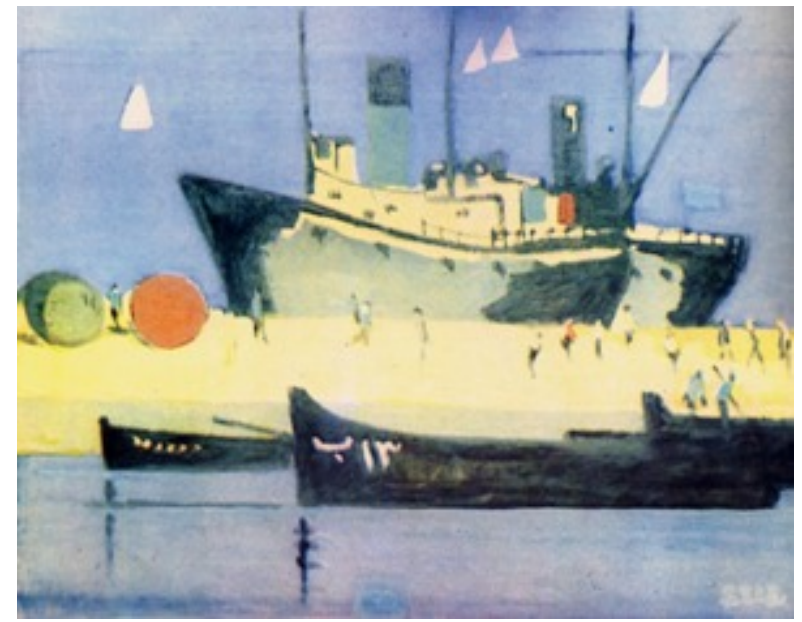

Figure (5)

Seif Wanly was known to be a very diverse artist characterized by his creativity and love for innovation as his personality is similar to that of Alexandria, he is open and accepting of the civilizations of the world. This enriched Alexandria's heritage during the times of the Ptolemies and the Romans and also in newer ages when it was the home of many European artists with all their diverse schools of thought. If Seif Wanly lived in another city in Egypt, his art wouldn't have been portrayed in the way that it is, as the essence of Alexandria coincided with Wanly's thought.

In the painting "boats in the port" (1957) Figure (6) which was created based on a different approach and vision inspired by the techniques of artists (art collage) without resorting to the mechanism of cutting and pasting, and to become consistent with the visions of modern art. He sought to flatten in the treatment of forms, adding a special character that distinguishes his style, which reflects the nature of the city of Alexandria.

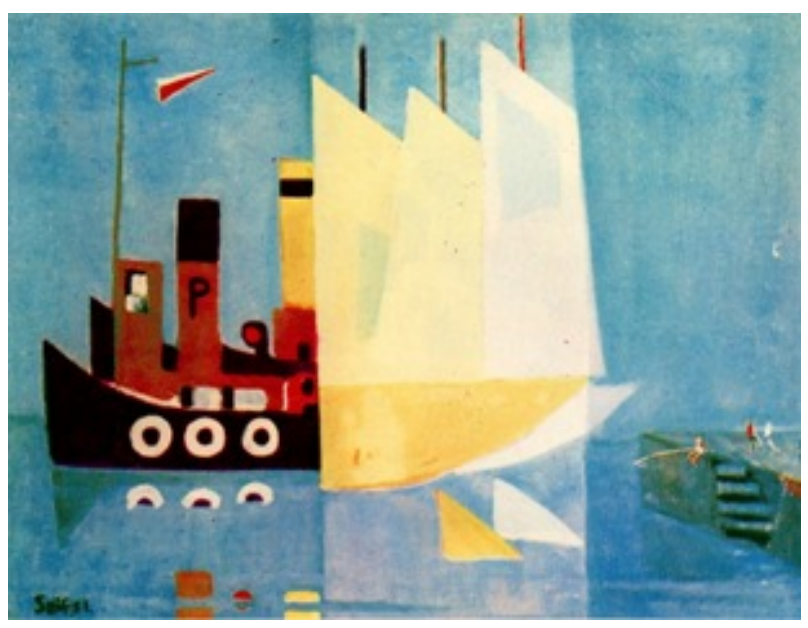

Figure (6)

\section{The Artist, "Adham Wanli"}

The artist "Adham Wanli" has been keen on the subject of popular and spontaneous tendency to record the nature of human feelings and the spirit of fun derived from his proficiency in caricature art, which reflected on the technical handling of the forms of many of the subjects of his paintings. This is especially true in works that reflected the lives of the simple local people as he depicted the way of life in this renowned city and mingled with musicians and clowns that performed on the pavements of the sea in the streets of Alexandria. This is evident in his painting “streets clowns of Alexandria” (1951) Figure (7), where a simple person is shown interacting with people on the street and he seems joyful as he’s drawn using vivid colors that reflect deep meanings. 


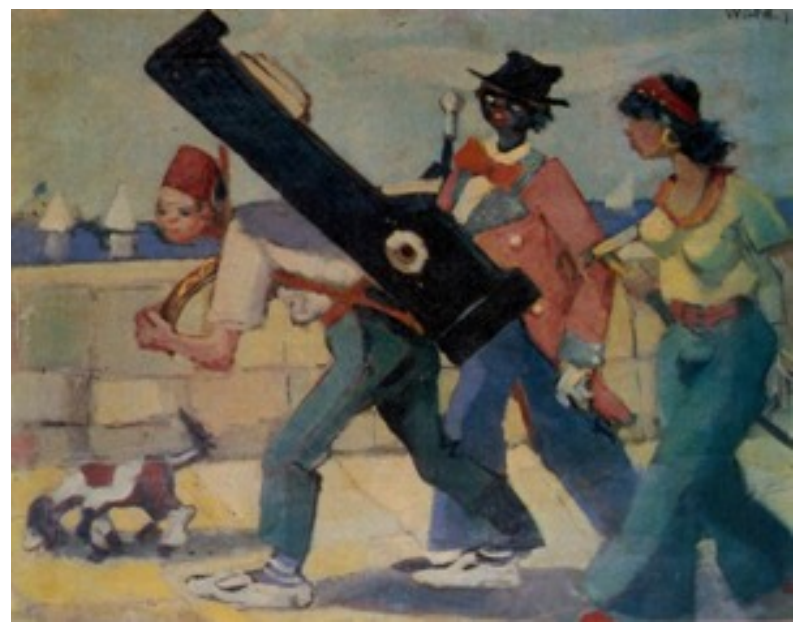

Figure (7)

Adham Wanli was one of the most brilliant artists who painted the teams that visited Egypt and presented her theatre arts, ballet performances, and circus acts. We see in the painting "Ballet de Pascoli" (1948) Figure (8) and the painting "Ballet sparrow Blue” (1948) Figure (9) where Adham Wanli depicted ballet and opera scenes as if he was reporting live on the events using his paint brush. His talent makes all the viewers relate to these events as if they are living in them, and his paintings also reflected his own joyful self. Given that his paintings also used the caricature art style, was consistent with the method of expressive execution that makes us feel like he drew these paintings while actually these performances.

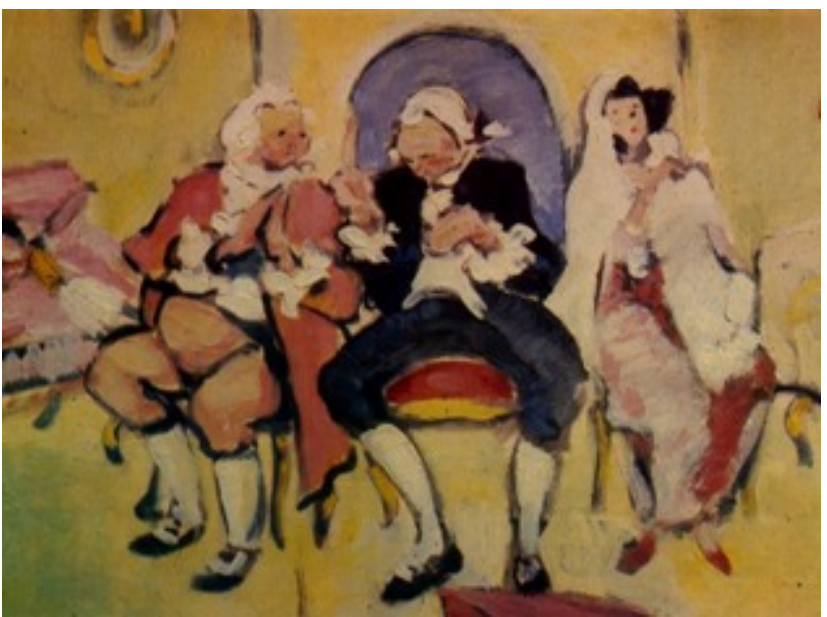

Figure (8)

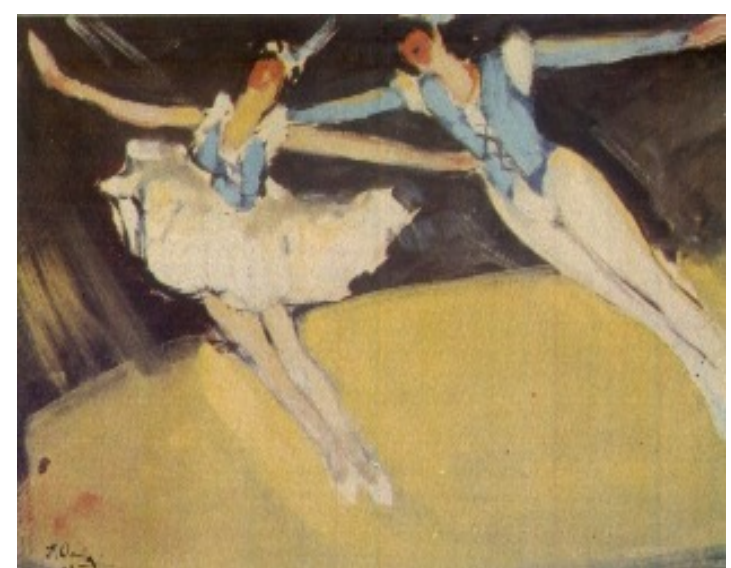

Figure (9)

\section{Turning to one of the pioneers of modern Egyptian Fine Art}

"Hamid Aweys" (1919- 2011), who is originally from the city of Beni Suef and later moved to Alexandria in 1948 in which he spent most of his years. In this highly creative environment, the artist Hamed Aweys designed works that are considered to be the most important constructions of his artistic milieu, where the sea and its style with the sky are shown, in this he reflects the views that he missed when living in Cairo. He was very loyal to the city of Alexandria and was inspired by the characteristics of the city and its environment that depict the struggles of the lower class that consists of farmers, fishermen, craftsmen, and other workers. He is also considered one of the artists that depict the real environment. He was also one of the artists who supported the 1952 revolution and this was very clear in his work.

Aweys was very concerned with humanitarian issues and he portrayed the everyday lives of people in his work. He set forth his perspective of all the people depicted, as he saw them as warriors that fought their everyday struggles valiantly. He used the beauty of his art to highlight all these humanitarian issues. This is evident in his famous painting “hunter's dialogue,” (1956) Figure (10) that shows three fishermen holding each other closely and discussing an important matter while sitting on the pavement of Alexandria's sea port. The artist outlined their featured in black to show the close relationship between them. 


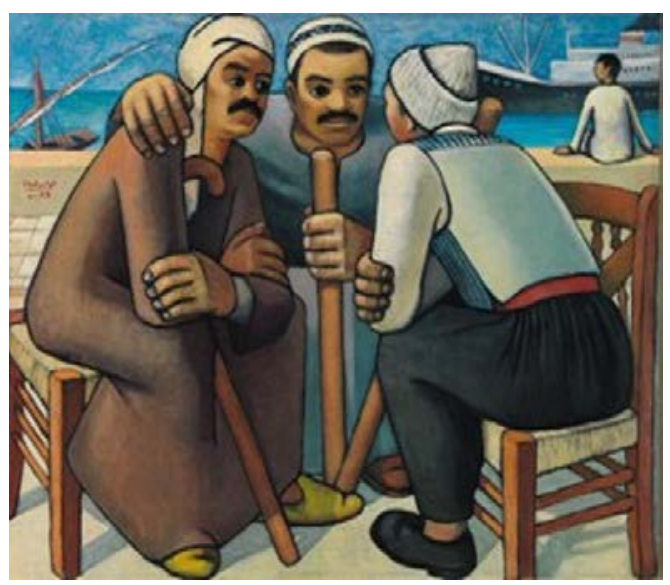

Figure (10)

As for the image of the woman, it played a very important and diverse role in his artwork. In Aweys' creative journey, his artistic language started to adopt some characteristics of sculpturing within the frame of the painting while still preserving his emptions towards the city of Alexandria. This is what is shown in his painting: "Country Girl” (1967) Figure (11) which is focused on depicting the sensuality and formality of young Alexandrian feminine girls. The girl in the painting was wearing a modern gown and wearing a bag and carrying a book, which reflect the artist's belief in the importance of female education. The girl in the painting has two pigeons next to her and several plants. The girl in the spotlight, as opposed to the other two girls behind her, showed her hair and revealed her typical Egyptian face to show her keenness to develop herself and become a women of science.

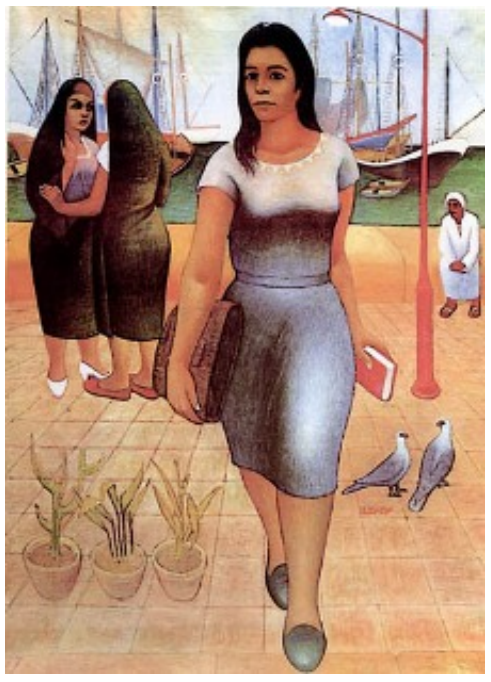

Figure (11)

Aweys developed a new straightforward way of depicting the life of the average Egyptian worker. Farmers or fishermen are shown with big, muscular bodies, which reflect the strength and stature of these men within the community and reflecting the power of social convictions, through his revolution on academic and smashing form and rules of anatomy. An example of his work is the painting titled "Fisherman and the fish" (1987) Figure (12), in which he demonstrates his accuracy in drawing as he showed the fisherman's nerve on his right arm. We can also see the ships in the back with their sails accurately drawn, the accuracy of the sky and the color of the sea and the sky, these together actually tell the story of this painting. 


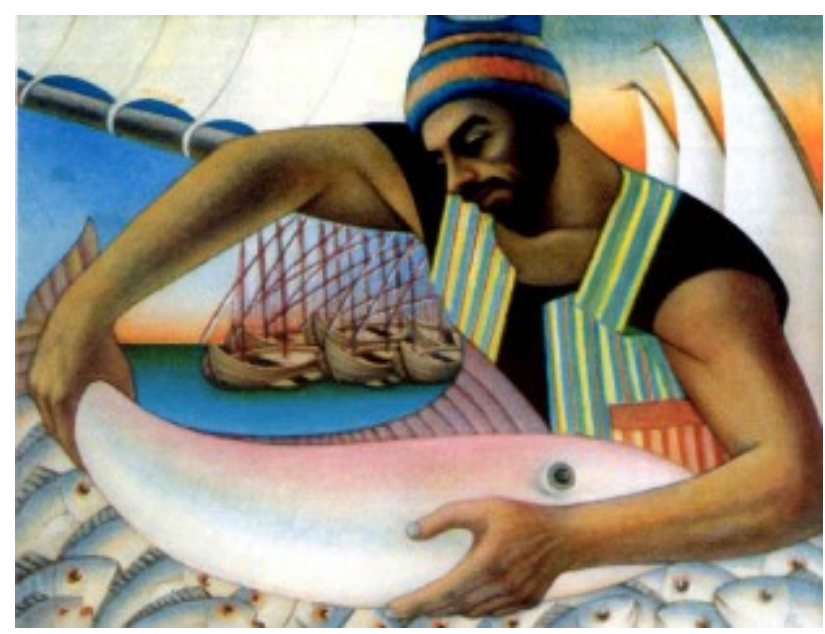

Figure (12)

\section{Conclusion}

The environmental circle surrounding the artist remains the most important force for his creativity, especially if we consider it to be built on several pillars, such as historical, geographic, cultural, political and social heritage, which in its entirety constitutes the autobiography of any nation seeking excellence among its peers. Each artist emphasized in his works his loyalty and affiliation with the environment of Alexandria and used it to extend to the horizons of the world. Aside from their humanitarian characteristics, we find their paintings are greatly influenced by Alexandria with all its cultural and social components and its environment with a mixture of unique overlapping cultures and customs of foreign communities and patterns of behavior while still considering the warmth of Alexandria's people towards foreigners.

\section{Photo Index}

\begin{tabular}{|c|l|l|l|}
\hline $\begin{array}{c}\text { Figure } \\
\text { No. }\end{array}$ & \multicolumn{1}{|c|}{ Work Name } & \multicolumn{1}{|c|}{ Raw material and size } & \multicolumn{1}{|c|}{ Collectibles } \\
\hline 1 & Blue robe (1927) & Oil paints on Canvas & Museum of Modern Art \\
\hline 2 & Beautiful sea (1935) & Oil paints on Canvas & $\begin{array}{l}\text { Group Mahmoud Khalil } \\
\text { Museum }\end{array}$ \\
\hline 3 & Strange Fishing (1933) & Oil paints on Canvas & $\begin{array}{l}\text { Group of the Egyptian } \\
\text { embassy in Washington }\end{array}$ \\
\hline 4 & Regilito Opera (1948) & Oil paints on paper -size $33 \times 46 \mathrm{~cm}$ & \\
\hline 5 & Alexandria Port (1952) & Oil paints on Silutks- size $50 \times 66 \mathrm{~cm}$ & \\
\hline 6 & Boats in the port (1957) & Oil paints on Silutks - Size $58 \times 74 \mathrm{~cm}$ & \\
\hline 7 & Streets Clowns in & Oil paints on Silutks - Size $80 \times 62 \mathrm{~cm}$ & \\
\hline 8 & Ballexandria (1951) & & \\
\hline 9 & Ballet Blue Bird "(1948) & Oil paints on paper -size $50 \times 35 \mathrm{~cm}$ & \\
\hline 10 & Fisherme Dialogue "(1956) & Oil paints on canvas girth size $79 \times 98 \mathrm{~cm}$ & Arab Museum of Modern Art \\
\hline 11 & Country girl "(1967) & Oil paints on canvas - Size $134 \times 100 \mathrm{~cm}$ & \\
\hline 12 & Fisherman and fish (1987) & Oil paints on canvas - Size $110 \times 91 \mathrm{~cm}$ & \\
\hline
\end{tabular}




\section{References}

Abogazi, B.E. (May 1985), Pioneers of Fine Art .

Najib, I.D. (1985) The dawn of modern Egyptian painting. Future House.

Saad El Din, M. (2002), Between materialism and spirituality. Arab Renaissance House.

Daustashi, I. (1997, April 8), Ministry of Culture. Cultural Development Fund.

Azar, E. (1961), Modern Painting in Egypt. Cairo.

Cranock, L. (2005), Modern Egyptian Art (1910-2003). The American University in Cairo Press.

Qassem, S. (2015), Artist Mahmoud Said. Memory of the Arts.

Qassem, S. (2017, January), Brothers Saif \& Adham and Wanli. Memory Arts.

Nawar, A. (2004), Hamed Aweys Egyptian artist. Journal of Art.

Al-Nasser, M. (2005), Journal of half the world.

El Hawary, H.E. (2011, 29 September), Article by artist Hamed Aweys. Nahdet Misr Newspaper. 